\title{
Acute, subacute oral toxicity and Ames test of Py-mulin: an antibacterial drug candidate
}

\author{
Yuan Fan', Yunxing Fu², Yuhang Zhou', Yu Liu', Baocheng Hao ${ }^{1}$ and Ruofeng Shang ${ }^{1 *}$
}

\begin{abstract}
Background: Py-mulin is a new pleuromutilin derivative with potent antibacterial activities in vitro and in vivo, suggesting this compound may lead to a promising antibacterial drug after further development. The present study is aimed to evaluate the acute and subacute oral toxicity, and the genotoxicity with the standard Ames test according to standard protocols.

Methods: Acute oral toxicity of Py-mulin was determined using Kunming mice. The 28-day repeated dose oral toxicity study in SD rats was performed according to OECD guideline No. 407. The bacterial reverse mutation (Ames test) was carried out using four Salmonella typhimurium (S. typhimurium) strains TA97, TA98, TA100 and TA1535 with and without $\mathrm{S} 9$ metabolic activation.

Results: The LD $D_{50}$ values in acute oral toxicity were $2973 \mathrm{mg} / \mathrm{kg}$ (female mice) and $3891 \mathrm{mg} / \mathrm{kg}$ (male mice) calculated by the Bliss method. In subacute toxicity study, $50 \mathrm{mg} / \mathrm{kg}$ Py-mulin did not induce any abnormality in body weight, food consumption, clinical sign, hematology, clinical chemistry, organ weight, and histopathology in all of the treatment groups. However, high doses of Py-mulin (100 and $300 \mathrm{mg} / \mathrm{kg}$ ) displayed slightly hepatotoxicity to female rats. Furthermore, Py-mulin did not significantly increase the number of revertant colonies of four standard S. typhimurium strains with the doses of $0.16-1000 \mu \mathrm{g} /$ plate in the Ames study.
\end{abstract}

Conclusions: Based on our findings, our study provides some information for the safety profile of Py-mulin.

Keywords: Py-mulin, Acute toxicity, Subacute toxicity, Ames test

\section{Background}

Bacteria with drug- resistance are a significant public health concern $[1,2]$. Of particular concern are methicillin-resistant Staphylococcus aureus (MRSA) which caused more than 15,000 deaths in the U.S. each year [3]. Unfortunately, the spreading bacterial resistance makes most antibiotics lose efficiency [4]. Therefore, it is

\footnotetext{
*Correspondence: shangrf1974@163.com

${ }^{1}$ Key Laboratory of New Animal Drug Project, Gansu Province/Key Laboratory of Veterinary Pharmaceutical Development, Ministry of Agriculture and Rural Affairs/Lanzhou Institute of Husbandry and Pharmaceutical Sciences of

Chinese Academy of Agriculture Sciences, No. 335, Qilihe District, Lanzhou 730050, People's Republic of China

Full list of author information is available at the end of the article
}

absolutely necessary to find and develop novel antimicrobial agents that do not produce cross resistance to antibiotics used in clinic [5].

In 1951, pleuromutilin was first discovered as a natural compound. Its derivatives selectively interact with prokaryotic ribosomes and thus inhibit bacterial protein synthesis [6-8]. This interaction mode was further confirmed by the crystallography data of $50 \mathrm{~S}$ ribosomal subunit which were obtained from Deinococcus radiodurans in complex with tiamulin $[9,10]$.

After clarifying the structure of pleuromutilin in the 1960s, thousands of new derivatives were synthesized to improve it antimicrobial activity [11-13]. The

C C The Author(s). 2021 Open Access This article is licensed under a Creative Commons Attribution 4.0 International License, which permits use, sharing, adaptation, distribution and reproduction in any medium or format, as long as you give appropriate credit to the original author(s) and the source, provide a link to the Creative Commons licence, and indicate if changes were made. The images or other third party material in this article are included in the article's Creative Commons licence, unless indicated otherwise in a credit line to the material. If material is not included in the article's Creative Commons licence and your intended use is not permitted by statutory regulation or exceeds the permitted use, you will need to obtain permission directly from the copyright holder. To view a copy of this licence, visit http://creativecommons.org/licenses/by/4.0/. The Creative Commons Public Domain Dedication waiver (http://creativecommons.org/publicdomain/zero/1.0/) applies to the data made available in this article, unless otherwise stated in a credit line to the data. 
modification of the pleuromutilin glycolic ester, especially the presence of thioether group, has been shown to give derivatives with improved antibacterial activities $[14,15]$, and thus has led to four drugs: tiamulin, valnemulin, retapamulin and lefamulin [16-20]. Tiamulin and valnemulin were approved as veterinary antibiotics for swine dysentery, enzootic pneumonia and chronic respiratory disease in poultry $[16,17,21]$. Retapamulin was for human topical skin infections [19]. Lefamulin was recently approved by FDA for treatment of community-acquired bacterial pneumonia (CABP) [20].

Py-mulin (14-O-[(4-Amino-6-hydroxy-pyrimidine-2yl) thioacetyl] mutilin) is a new pleuromutilin derivative with a pyrimidine moiety. This compound displayed excellent antibacterial activity in vitro and in vivo against Staphylococcus aureus (S. aureus), MRSA and Bacillus subtilis (B. subtilis) [22]. Here we conducted acute and subacute oral toxicity and Ames test to provide data for demonstrating its safety.

\section{Methods \\ Chemicals}

Py-mulin (white powder) was synthesized in our lab and the synthetic pathway and confirmations of it structure by IR, NMR and HR-MS spectrometry were described previously [22]. The purity of Py-mulin was checked by HPLC analyses with $99.2 \%$. During the study, the test sample was stored in the dark at a temperature of $4{ }^{\circ} \mathrm{C}$ and dissolved in DMSO freshly before use. All the other chemicals and solvents used were obtained from standard vendors and used without further purification.

\section{Animals}

Adult specific pathogen free (SPF) Kunming mice (4-5 weeks old) and Sprague-Dawley (SD) rats (4-6 weeks old) were purchased from the Laboratory Animal Center of Lanzhou University (Lanzhou, China). The animals were separated by sex, housed in clean stainless steel cages (two rat per cage, three mice per cage), free access to food and water, and maintained under the $23^{\circ} \mathrm{C}$ conditions with a constant $12 \mathrm{~h}$ light-dark cycle. Animals were acclimated for at least 7 days prior to the experiment. All experiments were carried out between 08:30 AM and 17:30 PM. The experimental procedures were performed in accordance with the Ethical Principles in Animal Research and were approved by the Committee for Ethics in the Laboratory Animal Center of Lanzhou University (number: SCXK20130002). The study was carried out in compliance with the ARRIVE guidelines.

\section{Acute Oral toxicity in mice}

After being stratified by weight, the SPF mice (30 male and 30 female, initial weight of 20.2-24.1 g and 19.3-21.8 g, respectively) were randomly assigned to six groups, including five treatment groups and one vehicle control group (5 female and 5 male mice for each group). The vehicle control group received only vehicle (ethyl oleate:1,2-propanediol: tween-80: sterile water $=4: 10: 31: 55$ ) in a volume of $10 \mathrm{~mL} /$ $\mathrm{kg}$ body weight (b.w.) by oral gavage. After mice were fasted for $3 \mathrm{~h}$, Py-mulin was dissolved in vehicle and orally administered to the mice at doses of 55, 175, 550, 1750 and 5000 $\mathrm{mg} / \mathrm{kg}$ b.w. (with volume of $10 \mathrm{~mL} / \mathrm{kg}$ ), respectively. Vehicle or Py-mulin was administered only once (on day 0 ) and animals were observed for next 14-days post treatment. All mice were observed twice daily for behavioural symptoms and mortality for two week. Individual body weights were recorded on days 0,7 and 14. All of the surviving animals were euthanized by anesthetized with pentobarbital sodium $0.06 \mathrm{~g} / \mathrm{kg}$ (i.p.) at the end of the observation period of 14 days, and their vital organs were individually observed for overt pathology by necropsy. Finally, the $\mathrm{LD}_{50}$ and $95 \%$ confidence interval for female and male mice were calculated by the probit weighted regression method (Bliss method) using IBM SPSS Statistics for Windows version 24.0 (SPSS Inc., Chicago, USA).

\section{Subacute toxicity \\ Study design}

The subacute toxicity study of Py-mulin was performed according to OECD guideline No. 407 [23]. Female and male SD rats (initial weight of $126.3-145.6 \mathrm{~g}$ and $141.2-158.1 \mathrm{~g}$, respectively) were randomly divided into four groups after one week of acclimatization. Each group consisted of $10 \mathrm{fe}-$ male rats and 10 male rats. Doses were determined based on the result of acute oral toxicity. Py-mulin was dissolved in vehicle (ethyl oleate:1,2-propanediol:tween-80: sterile water $=4: 10: 31: 55)$ and administrated to rats by oral gavage at doses of 50,100 and $300 \mathrm{mg} / \mathrm{kg}$ bw or control $(4 \mathrm{~mL} / \mathrm{kg}$ bw vehicle) for 28 days (administration at the same time each day $\pm 1 \mathrm{~h}$ ). All the animals were observed once daily to detect toxic symptoms. During the whole experiment, body weight and food consumption were measured every week and the gavage volume was adjusted based on the last measured body weight.

\section{Clinical observations}

During the 28-day treatment, for all the rats, behavioral changes, symptoms and signs of gross toxicity, food consumption, water intake and mortality were closely observed at least once per day. The individual body weights of the rats and food consumption were measured weekly. The mean weekly body weight gain and daily food consumption were calculated for each sex animal and dose level.

\section{Haematological and biochemical analysis}

At the end of the experiment, following an overnight fast, rats were anesthetized with excess of $\mathrm{CO}_{2}$ and euthanized 

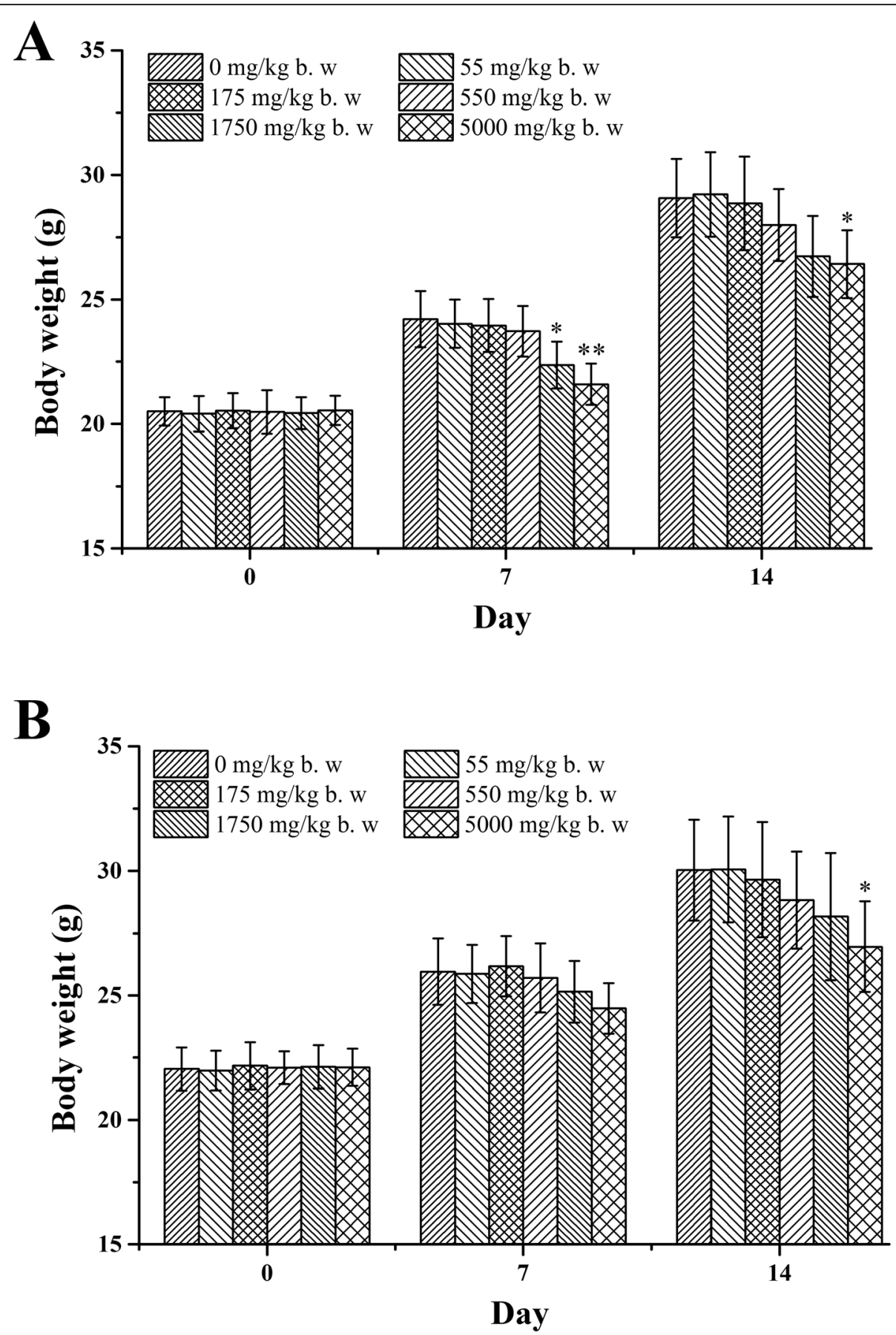

Fig. 1 Body weight gain of female $(\mathbf{A})$ and male $(\mathbf{B})$ mice administered with Py-mulin. The results are expressed as mean $\pm S D$. ${ }^{*} p<0.05$ versus 0 $\mathrm{mg} / \mathrm{kg}$ b. w. group

by exsanguination. Blood sample $(5 \mathrm{~mL})$ of animal in each group were collected from the femoral artery in ethylenediaminetetraacetic acid (EDTA) coated tubes and nonheparinized tubes for the haematological and biochemical analysis, respectively [24]. The haematological parameters, including the white blood cell (WBC), the hemoglobin (HGB), red blood cell (RBC) counts, hematocrit (HCT) levels, mean corpuscular hemoglobin $(\mathrm{MCH})$, mean corpuscular volume (MCV), mean corpuscular haemoglobin concentration (MCHC) and number of platelets (PLT), were determined using a Poche-100iv Diff instrument (SYSMEX, Kakogawa, Japan). The biochemical parameters measured were alanine transaminase (ALT), aspartate transaminase (AST), alkaline phosphatase (ALP), total bilirubin 

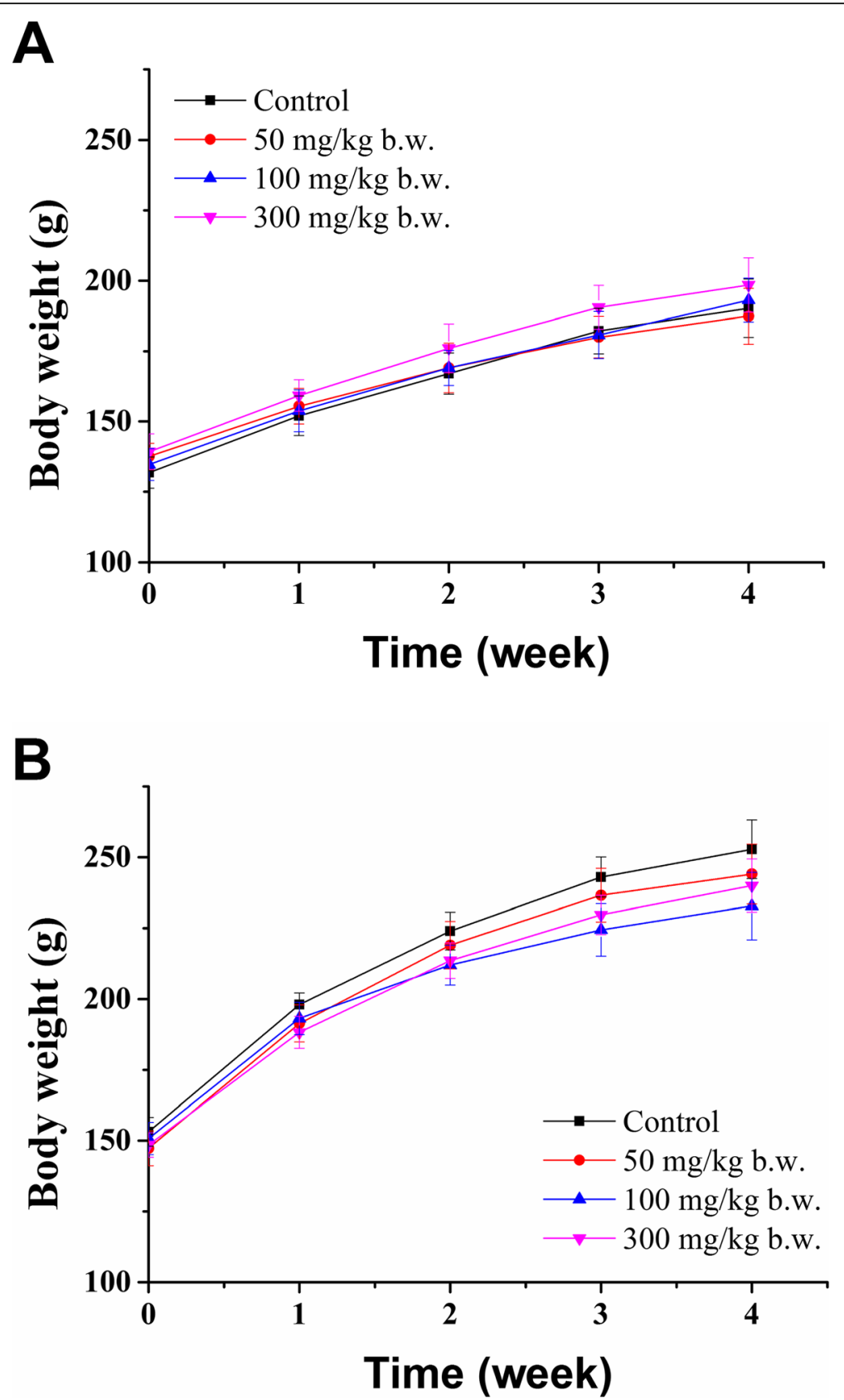

Fig. 2 Body weight of female (A) and male (B) rats in subacute toxicity study of Py-mulin $(n=10)$

(TB), total cholesterol (TC), low density lipoprotein (LDL), high density lipoprotein (HDL), triglycerides (TG), urea nitrogen (UN), creatinine (Crea), total protein (TP), glucose (Glu), albumin (Alb), calcium (Ca) and phosphorous (P), using reagent kits and a Mindray BS-420 auto hematology analyzer (Mindray Corporation, Shenzhen, China).

\section{Macroscopic examination and organ weights}

After necropsy, each rat was examined for the external surface, visceral organs and all orifices, followed by recording the gross pathological changes. Finally, the heart, liver, spleen, lungs, kidneys, thymus, testes or ovaries were collected and weighed. The relative organ weight (organ/body-weight ratio) was calculated based on the final animal's body weight.

\section{Histopathologic examination}

Histopathological examinations were performed on the kidneys, spleen, heart, liver, thymus, lungs, small intestines, testes or ovaries of randomly selected five female and five male rats using a routine paraffin-embedding technique. The organs were preserved in $10 \%$ neutral- 
Table 1 Haematology parameters of rats sacrificed on day 28 of 28-day feeding test (Mean \pm SD)

\begin{tabular}{|c|c|c|c|c|}
\hline Parameters & $0 \mathrm{mg} / \mathrm{kg} \mathrm{b.} \mathrm{w.}$ & $50 \mathrm{mg} / \mathrm{kg}$ b. w. & $100 \mathrm{mg} / \mathrm{kg} \mathrm{b.} \mathrm{w.}$ & $300 \mathrm{mg} / \mathrm{kg}$ b. w. \\
\hline \multicolumn{5}{|l|}{ Female } \\
\hline WBC & $5.47 \pm 1.11$ & $4.94 \pm 1.33$ & $4.16 \pm 1.08$ & $4.83 \pm 1.48$ \\
\hline $\mathrm{RBC}$ & $8.33 \pm 0.98$ & $6.82 \pm 1.01^{*}$ & $7.85 \pm 0.50$ & $7.50 \pm 0.53$ \\
\hline HGB & $141.42 \pm 8.77$ & $131.37 \pm 7.91$ & $135.16 \pm 5.94$ & $139.01 \pm 7.24$ \\
\hline $\mathrm{HCT}$ & $40.96 \pm 1.66$ & $43.88 \pm 2.51$ & $41.24 \pm 1.61$ & $44.01 \pm 1.87^{*}$ \\
\hline MCV & $57.21 \pm 1.32$ & $58.56 \pm 1.08$ & $56.73 \pm 1.43$ & $56.84 \pm 1.22$ \\
\hline $\mathrm{MCH}$ & $21.60 \pm 0.79$ & $22.07 \pm 0.95$ & $20.81 \pm 0.98$ & $21.13 \pm 0.88$ \\
\hline $\mathrm{MCHC}$ & $357.47 \pm 12.04$ & $360.10 \pm 10.35$ & $348.17 \pm 19.45$ & $350.26 \pm 13.55$ \\
\hline PLT & $1011.28 \pm 124.25$ & $911.31 \pm 118.19$ & $1180.69 \pm 158.54$ & $915.68 \pm 135.97$ \\
\hline \multicolumn{5}{|l|}{ Male } \\
\hline WBC & $7.34 \pm 1.56$ & $8.21 \pm 1.73$ & $6.90 \pm 2.11$ & $7.67 \pm 1.26$ \\
\hline $\mathrm{RBC}$ & $8.37 \pm 0.67$ & $8.48 \pm 0.88$ & $7.88 \pm 0.72$ & $8.73 \pm 0.90$ \\
\hline $\mathrm{HGB}$ & $145.84 \pm 7.90$ & $139.36 \pm 8.40$ & $138.26 \pm 6.99$ & $143.52 \pm 9.31$ \\
\hline $\mathrm{HCT}$ & $40.72 \pm 1.37$ & $40.22 \pm 1.83$ & $41.91 \pm 1.60$ & $39.86 \pm 2.51$ \\
\hline MCV & $57.75 \pm 1.30$ & $55.98 \pm 0.98^{*}$ & $58.24 \pm 1.31$ & $59.03 \pm 1.04$ \\
\hline $\mathrm{MCH}$ & $21.67 \pm 0.87$ & $20.89 \pm 0.93$ & $21.32 \pm 0.75$ & $21.56 \pm 0.87$ \\
\hline $\mathrm{MCHC}$ & $341.83 \pm 15.83$ & $352.21 \pm 21.01$ & $354.37 \pm 11.90$ & $360.81 \pm 19.39$ \\
\hline PLT & $952.67 \pm 142.45$ & $893.28 \pm 107.30$ & $995.37 \pm 135.60$ & $979.47 \pm 150.94$ \\
\hline
\end{tabular}

Abbreviations: WBC white blood cells $\left(10^{9} / \mathrm{L}\right), R B C$ red blood cells $\left(10^{12} / \mathrm{L}\right), H G B$ hemoglobin $(\mathrm{g} / \mathrm{L}), H C T$ hematocrit $(\%), M C V$ mean corpuscular volume, $M C H$ mean corpuscular hemoglobin, MCHC mean corpuscular hemoglobin concentration, PLT platelets $\left(10^{3} / \mu \mathrm{L}\right)$. Values represent means $\pm \mathrm{SD}$. ${ }^{*} p<0.05 \mathrm{vs}$. control group $(0$ $\mathrm{mg} / \mathrm{kg} \mathrm{b.} \mathrm{w.)}$

buffered formalin, and their slides were prepared. Upon completion of staining with hematoxylin and eosin (H\&E), microscopic examinations were performed on all the mentioned tissues.

\section{Ames test}

S. typhimurium strains, including TA97, TA98, TA100 and TA1535, were first checked for their genetic integrity. Biotin dependence, $r f a$ marker (crystal violet), biotin and histidine dependence, histidine dependence and presence of the plasmid pKM101 (ampicillin resistance) or pAQ1 (tetracycline resistance) were then tested. Different strains were used to identify different types of mutations.

The test was performed with five concentrations of Py-mulin. After weighing accurately, $100 \mathrm{mg}$ Py-mulin was dissolved in DMSO $(2 \mathrm{~mL})$ and the obtained solution $(1 \mathrm{~mL})$ was diluted by fivefold with distilled water. The $0.5 \mathrm{~mL}$ obtained serial dilutions were diluted with $9.5 \mathrm{~mL}$ melted top agar to the desired concentrations (500, 100, 20, 4 and $0.8 \mu \mathrm{g} / \mathrm{mL})$. DMSO $(0.5 \mathrm{~mL})$ was directly incorporated into $9.5 \mathrm{~mL}$ melted top agar (the final concentrations was $100 \mu \mathrm{L} /$ plate) as the vehicle control. For all bacterial strains, 2-aminofluorene and fenaminosulf (the final concentration of $10 \mu \mathrm{L} /$ plate) were used as positive control with and without S9, respectively. As described in the literatures [25, 26], the
Ames test was conducted with some modifications. Each strain $(1 \mathrm{~mL})$ was inoculated into $5 \mathrm{~mL}$ of nutrient broth, followed by incubating overnight at $37^{\circ} \mathrm{C}$. The mixture comprised respective strains, DMSO, 2-aminofluorene and drug for testing with the S9. For testing without S9, $1 \times$ phosphate buffer saline (PBS, $\mathrm{pH} 7.4$ ) replaced the S9 mix. The obtained mixtures were then added into the tube, mixed well and incubated $\left(20 \mathrm{~min}\right.$ at $\left.37^{\circ} \mathrm{C}\right)$. Then, the top agar $(2 \mathrm{~mL})$ was melted and added to each tube and gently mixed, followed by pouring onto the surface of glucose minimal (GM) agar plate (the final concentrations of Py-mulin were 1000, 200, 40, 8 and $1.6 \mu \mathrm{g} /$ plate, respectively, and the final concentrations of DMSO was $100 \mu \mathrm{L} /$ plate). The plate was then swirled to distribute the overlay agar to all surfaces of GM agar, followed by inverting and incubation $\left(37^{\circ} \mathrm{C}\right.$ for $48 \mathrm{~h}$ ) when the top agar solidified. The resultant colonies were counted manually as the number of revertant colonies per plate. The experiments were performed in triplicate.

\section{Statistical analysis}

We used IBM SPSS Statistics for Windows version 24.0 [27] to perform the statistical analysis. Using One-way analysis of variance (ANOVA) and Dunnett's post-hoc tests as appropriate analyzed the data. Statistical significant difference was defined as a $p<0.05$ and the extremely significant difference was defined as a $p<0.01$. 
Table 2 Biochemical parameters of rats sacrificed on day 28 of 28-day feeding test (Mean \pm SD)

\begin{tabular}{|c|c|c|c|c|}
\hline Parameters & $0 \mathrm{mg} / \mathrm{kg}$ b. w. & $50 \mathrm{mg} / \mathrm{kg}$ b. w. & $100 \mathrm{mg} / \mathrm{kg}$ b. w. & $300 \mathrm{mg} / \mathrm{kg}$ b. w. \\
\hline \multicolumn{5}{|l|}{ Female } \\
\hline ALT (U/L) & $44.01 \pm 5.89$ & $45.64 \pm 6.73$ & $59.08 \pm 6.99^{* *}$ & $51.78 \pm 4.82^{*}$ \\
\hline ALP (U/L) & $243.86 \pm 36.02$ & $196.54 \pm 42.84$ & $220.15 \pm 45.12$ & $198.22 \pm 36.86$ \\
\hline AST (U/L) & $117.47 \pm 23.55$ & $108.93 \pm 26.11$ & $122.98 \pm 24.20$ & $118.80 \pm 23.07$ \\
\hline TB $(\mu \mathrm{mol} / \mathrm{L})$ & $2.91 \pm 0.40$ & $2.25 \pm 0.37^{*}$ & $3.08 \pm 0.43$ & $2.34 \pm 0.47$ \\
\hline TC (mmol/L) & $1.54 \pm 0.23$ & $1.57 \pm 0.19$ & $1.70 \pm 0.18$ & $1.41 \pm 0.15$ \\
\hline $\mathrm{HDL}(\mathrm{mmol} / \mathrm{L})$ & $0.47 \pm 0.05$ & $0.54 \pm 0.06$ & $0.57 \pm 0.08^{*}$ & $0.45 \pm 0.07$ \\
\hline LDL (mmol/L) & $0.78 \pm 0.08$ & $0.80 \pm 0.06$ & $0.86 \pm 0.06$ & $0.79 \pm 0.06$ \\
\hline TG (mmol/L) & $0.67 \pm 0.34$ & $0.74 \pm 0.40$ & $0.82 \pm 0.39$ & $0.71 \pm 0.27$ \\
\hline Crea $(\mu \mathrm{mol} / \mathrm{L})$ & $39.65 \pm 6.73$ & $38.08 \pm 5.78$ & $36.76 \pm 6.78$ & $40.29 \pm 6.26$ \\
\hline UN (mmol/L) & $6.97 \pm 0.67$ & $7.09 \pm 0.77$ & $5.89 \pm 0.68^{*}$ & $6.74 \pm 0.47$ \\
\hline $\mathrm{TP}(\mathrm{g} / \mathrm{L})$ & $64.77 \pm 4.99$ & $60.92 \pm 5.38$ & $65.69 \pm 5.50$ & $58.89 \pm 4.69$ \\
\hline Alb (g/L) & $31.33 \pm 3.39$ & $31.17 \pm 3.03$ & $30.28 \pm 4.53$ & $30.03 \pm 3.68$ \\
\hline Glu (mmol/L) & $5.62 \pm 0.68$ & $6.18 \pm 0.50$ & $6.15 \pm 0.45$ & $5.59 \pm 0.59$ \\
\hline $\mathrm{Ca}(\mathrm{mmol} / \mathrm{L})$ & $2.64 \pm 0.50$ & $2.39 \pm 0.38$ & $2.56 \pm 0.52$ & $2.38 \pm 0.46$ \\
\hline $\mathrm{P}(\mathrm{mmol} / \mathrm{L})$ & $3.00 \pm 0.25$ & $2.64 \pm 0.31$ & $2.79 \pm 0.30$ & $2.92 \pm 0.27$ \\
\hline \multicolumn{5}{|l|}{ Male } \\
\hline $\mathrm{ALT}(\mathrm{U} / \mathrm{L})$ & $52.45 \pm 5.76$ & $60.28 \pm 6.72$ & $47.93 \pm 5.46$ & $51.42 \pm 6.49$ \\
\hline $\mathrm{ALP}(\mathrm{U} / \mathrm{L})$ & $246.66 \pm 42.88$ & $257.62 \pm 37.88$ & $283.76 \pm 46.69^{*}$ & $222.44 \pm 40.11$ \\
\hline AST (U/L) & $110.45 \pm 24.35$ & $116.05 \pm 20.23$ & $125.27 \pm 26.17$ & $93.63 \pm 24.24$ \\
\hline TB $(\mu \mathrm{mol} / \mathrm{L})$ & $2.64 \pm 0.37$ & $2.93 \pm 0.54$ & $2.64 \pm 0.41$ & $2.10 \pm 0.46$ \\
\hline TC (mmol/L) & $1.54 \pm 0.16$ & $1.55 \pm 0.17$ & $1.61 \pm 0.21$ & $1.44 \pm 0.23$ \\
\hline $\mathrm{HDL}(\mathrm{mmol} / \mathrm{L})$ & $0.52 \pm 0.08$ & $0.50 \pm 0.05$ & $0.57 \pm 0.09$ & $0.54 \pm 0.08$ \\
\hline LDL (mmol/L) & $0.85 \pm 0.08$ & $0.88 \pm 0.06$ & $0.85 \pm 0.04$ & $0.80 \pm 0.07$ \\
\hline TG (mmol/L) & $0.69 \pm 0.38$ & $0.75 \pm 0.40$ & $0.86 \pm 0.33$ & $0.59 \pm 0.30$ \\
\hline Crea ( $\mu \mathrm{mol} / \mathrm{L})$ & $36.00 \pm 4.61$ & $42.27 \pm 6.47$ & $35.52 \pm 5.65$ & $30.79 \pm 6.13$ \\
\hline UN (mmol/L) & $5.42 \pm 0.43$ & $5.16 \pm 0.49$ & $6.13 \pm 0.76$ & $5.08 \pm 0.56$ \\
\hline TP (g/L) & $62.83 \pm 4.85$ & $69.64 \pm 5.80$ & $68.36 \pm 4.76$ & $64.29 \pm 4.33$ \\
\hline Alb (g/L) & $30.20 \pm 4.02$ & $31.18 \pm 4.08$ & $30.90 \pm 3.55$ & $28.49 \pm 3.15$ \\
\hline Glu (mmol/L) & $4.24 \pm 0.55$ & $4.92 \pm 0.56$ & $4.04 \pm 0.49$ & $3.83 \pm 0.52$ \\
\hline $\mathrm{Ca}(\mathrm{mmol} / \mathrm{L})$ & $2.34 \pm 0.38$ & $2.53 \pm 0.51$ & $2.50 \pm 0.45$ & $1.97 \pm 0.38$ \\
\hline $\mathrm{P}(\mathrm{mmol} / \mathrm{L})$ & $2.83 \pm 0.21$ & $2.68 \pm 0.27$ & $3.05 \pm 0.25$ & $2.44 \pm 0.27^{*}$ \\
\hline
\end{tabular}

Abbreviations: ALT Alanine transaminase, ALP Alkaline phosphatase, AST Aspartate transaminase, TB Total bilirubin, TC Total cholesterol, HDL High density lipoprotein, $L D L$ low density lipoprotein, TG triglycerides, Crea Creatinine, UN Urea nitrogen, TP Total protein, Alb Albumin, Glu Glucose, Ca Calcium, $P$ phosphorous. Values represent means $\pm \mathrm{SD}$. ${ }^{*} p<0.05,{ }^{* *} p<0.01 \mathrm{vs}$. control group $(0 \mathrm{mg} / \mathrm{kg} \mathrm{b}$. w.)

\section{Results}

\section{Acute oral toxicity}

No animals died after receiving an oral dose of 55,175 and $550 \mathrm{mg} / \mathrm{kg}$ of Py-mulin. Conversely, Py-mulin caused 20 and $70 \%$ mortality which were found in both female and male animals at the dose of 1750 (one female and one male mice died) and $5000 \mathrm{mg} / \mathrm{kg}$ (four female and three male mice died) within three days, respectively. Using the Bliss method, the $\mathrm{LD}_{50}$ values were determined to be 2973 and $3891 \mathrm{mg} / \mathrm{kg}$ in female and male mice, with the confidence level of $95 \%$ was 975 to
$14,445 \mathrm{mg} / \mathrm{kg}$ and 1474 to $0.5599 \mathrm{mg} / \mathrm{kg}$, respectively. No clinical signs or adverse effects of toxicity were observed for the surviving animals receiving the dose of 55 , 175 and $550 \mathrm{mg} / \mathrm{kg}$ of Py-mulin during the study. Clinical signs, including lethargy, rough coat, prostration, squinting, gait disturbance and bradykinesia, of acute toxicity occurred in mice given single oral doses of 1750 and $5000 \mathrm{mg} / \mathrm{kg}$, appearing approximately 8 to $12 \mathrm{~h}$ after dosing. In female and male mice treated with Py-mulin, body weight generally increased throughout the study for all dose groups (Fig. 1). Compared to the control, 
Table 3 Absolute and relative organ weights from female rats treated orally with Py-mulin for 28 days

\begin{tabular}{|c|c|c|c|c|}
\hline Parameters & $0 \mathrm{mg} / \mathrm{kg}$ b.w. & 50 mg/kg b.w. & 100 mg/kg b.w. & $300 \mathrm{mg} / \mathrm{kg}$ b.w. \\
\hline \multicolumn{5}{|c|}{ Absolute organ weight (g) } \\
\hline Heart & $0.75 \pm 0.10$ & $0.70 \pm 0.10$ & $0.82 \pm 0.06$ & $0.81 \pm 0.07$ \\
\hline Liver & $6.89 \pm 0.83$ & $7.29 \pm 0.90$ & $7.65 \pm 1.01$ & $7.88 \pm 0.53^{*}$ \\
\hline Spleen & $0.44 \pm 0.08$ & $0.48 \pm 0.05$ & $0.42 \pm 0.08$ & $0.49 \pm 0.07$ \\
\hline Lungs & $1.04 \pm 0.11$ & $1.12 \pm 0.13$ & $1.08 \pm 0.12$ & $1.05 \pm 0.14$ \\
\hline Kidneys & $1.35 \pm 0.14$ & $1.39 \pm 0.17$ & $1.41 \pm 0.15$ & $1.43 \pm 0.17$ \\
\hline Thymus & $0.35 \pm 0.05$ & $0.37 \pm 0.06$ & $0.42 \pm 0.06$ & $0.41 \pm 0.07$ \\
\hline Ovaries & $0.09 \pm 0.02$ & $0.12 \pm 0.03$ & $0.11 \pm 0.03$ & $0.11 \pm 0.04$ \\
\hline \multicolumn{5}{|c|}{ Organ-to-body weight ratio (\%) } \\
\hline Heart & $0.39 \pm 0.04$ & $0.37 \pm 0.04$ & $0.42 \pm 0.03$ & $0.41 \pm 0.03$ \\
\hline Liver & $3.61 \pm 0.30$ & $3.88 \pm 0.33$ & $3.95 \pm 0.40$ & $3.97 \pm 0.10^{*}$ \\
\hline Spleen & $0.23 \pm 0.03$ & $0.26 \pm 0.03$ & $0.22 \pm 0.03$ & $0.25 \pm 0.03$ \\
\hline Lungs & $0.55 \pm 0.05$ & $0.59 \pm 0.04$ & $0.56 \pm 0.04$ & $0.52 \pm 0.06$ \\
\hline Kidneys & $0.71 \pm 0.05$ & $0.74 \pm 0.06$ & $0.73 \pm 0.07$ & $0.72 \pm 0.05$ \\
\hline Thymus & $0.18 \pm 0.02$ & $0.20 \pm 0.03$ & $0.22 \pm 0.02^{*}$ & $0.21 \pm 0.03$ \\
\hline Ovaries & $0.05 \pm 0.01$ & $0.06 \pm 0.02$ & $0.06 \pm 0.02$ & $0.06 \pm 0.02$ \\
\hline
\end{tabular}

Values are mean \pm SD for 10 rats in each group

*Statistically significant difference compared to control $(p<0.05)$

body weight of female mice was reduced by 7.64 and $10.82 \%$ at day 7 in the 1750 and $5000 \mathrm{mg} / \mathrm{kg}$ groups $(p<$ 0.05 and $p<0.01$, respectively). In the $5000 \mathrm{mg} / \mathrm{kg}$ group, compared to the control at day 14, body weight of female and male mice was reduced 9.12 and $10.22 \%(p<$ $0.05)$, respectively. At necropsy, no gross pathological abnormalities were found in any organs of the surviving animals receiving the dose of 55,175 and $550 \mathrm{mg} / \mathrm{kg}$ of Py-mulin. However, hemorrhage on the lungs, livers and small intestines were found in died mice during the treatment or some mice in higher dose groups (1750 and $5000 \mathrm{mg} / \mathrm{kg}$ group). Furthermore, drug precipitation

Table 4 Absolute and relative organ weights from male rats treated orally with Py-mulin for 28 days

\begin{tabular}{|c|c|c|c|c|}
\hline Parameters & $0 \mathrm{mg} / \mathrm{kg}$ b.w. & $50 \mathrm{mg} / \mathrm{kg} \mathrm{b.w.}$ & 100 mg/kg b.w. & $300 \mathrm{mg} / \mathrm{kg}$ b.w. \\
\hline \multicolumn{5}{|c|}{ Absolute organ weight (g) } \\
\hline Heart & $0.94 \pm 0.0 .09$ & $0.93 \pm 0.08$ & $0.88 \pm 0.13$ & $0.97 \pm 0.12$ \\
\hline Liver & $9.82 \pm 0.76$ & $9.55 \pm 0.53$ & $9.08 \pm 0.68$ & $9.69 \pm 0.40$ \\
\hline Spleen & $0.58 \pm 0.10$ & $0.54 \pm 0.11$ & $0.56 \pm 0.08$ & $0.52 \pm 0.07$ \\
\hline Lungs & $1.31 \pm 0.21$ & $1.25 \pm 0.16$ & $1.10 \pm 0.12$ & $1.17 \pm 0.13$ \\
\hline Kidneys & $1.89 \pm 0.22$ & $1.82 \pm 0.17$ & $1.75 \pm 0.19$ & $1.85 \pm 0.28$ \\
\hline Thymus & $0.44 \pm 0.07$ & $0.45 \pm 0.12$ & $0.34 \pm 0.06^{*}$ & $0.47 \pm 0.11$ \\
\hline Testis & $2.69 \pm 0.22$ & $2.68 \pm 0.18$ & $2.67 \pm 0.18$ & $2.72 \pm 0.23$ \\
\hline \multicolumn{5}{|c|}{ relative organ weight } \\
\hline Heart & $0.37 \pm 0.03$ & $0.38 \pm 0.03$ & $0.38 \pm 0.04$ & $0.40 \pm 0.04$ \\
\hline Liver & $3.88 \pm 0.24$ & $3.91 \pm 0.12$ & $3.90 \pm 0.14$ & $4.04 \pm 0.12$ \\
\hline Spleen & $0.23 \pm 0.03$ & $0.22 \pm 0.04$ & $0.24 \pm 0.03$ & $0.22 \pm 0.02$ \\
\hline Lungs & $0.52 \pm 0.06$ & $0.51 \pm 0.06$ & $0.47 \pm 0.03$ & $0.493 \pm 0.04$ \\
\hline Kidneys & $0.74 \pm 0.06$ & $0.75 \pm 0.04$ & $0.75 \pm 0.08$ & $0.77 \pm 0.09$ \\
\hline Thymus & $0.17 \pm 0.02$ & $0.18 \pm 0.04$ & $0.15 \pm 0.03$ & $0.19 \pm 0.04$ \\
\hline Testis & $1.06 \pm 0.05$ & $1.10 \pm 0.07$ & $1.15 \pm 0.06^{*}$ & $1.13 \pm 0.06$ \\
\hline
\end{tabular}



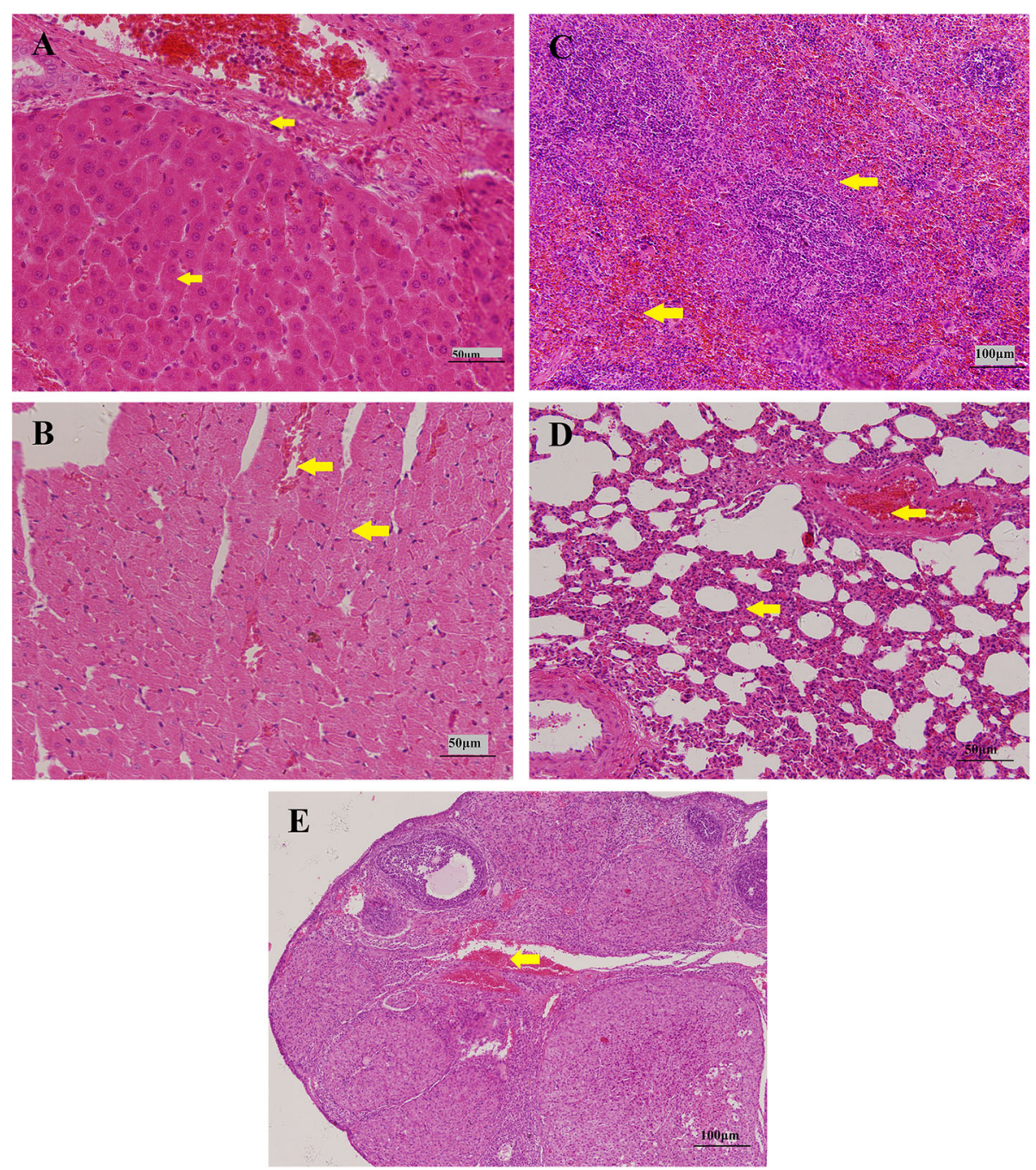

Fig. 3 Selected microphotographs (H\&E $\times 100)$ of tissues in rats during 28 days repeated dose toxicity study. A: liver (300 mg/kg b.w., female), inflammatory cells and edema; B: heart (100 mg/kg b.w., female), erythrocytosis and edema; C: spleen (100 mg/kg b.w., male), erythrocytosis and congestion; D lung (50 mg/kg b.w., female), connective tissues proliferation and congestion; E: ovaries (100 mg/kg b.w., female), congestion

was also found in the stomachs of some died mice at the early days which were given high dose of $5000 \mathrm{mg} / \mathrm{kg}$ of Py-mulin.

\section{Subacute 28 days study Observational study, body weights, food consumption and water intake}

No deaths or obvious clinical signs related to toxicity were observed in any treated groups or the vehicle control group throughout the 28-day experimental period. The body weights of animals are shown in Fig. 2. Food and water consumption for all rats in control and treated groups were normal and similar at any time point.

\section{Haematology and clinical biochemistry}

Hematological values of rats treated orally with Py-mulin for 28 days are shown in Table 1. Compared with the negative control, $\mathrm{RBC}$ in females and $\mathrm{MCV}$ in males significantly decreased in $50 \mathrm{mg} / \mathrm{kg}$ dose of Py-mulin treated groups $(p<0.05)$, while HCT in females $(300 \mathrm{mg} / \mathrm{kg})$ significantly increased $(p<0.05)$. However, for the other haematological parameters, no significant difference was observed between the treated groups and the control group.

After administration of Py-mulin, significant changes were also observed in clinical chemistry analyses (Table 2), included increased ALT in females (100 and $300 \mathrm{mg} / \mathrm{kg}, p<0.01$ and 0.05 , respectively), decreased TB in female $(50 \mathrm{mg} / \mathrm{kg}, p<0.05)$, increased HDL in females $(100 \mathrm{mg} / \mathrm{kg}, p<0.05)$, decreased UN in female $(100 \mathrm{mg} / \mathrm{kg}, p<0.05)$, increased ALP in male $(100 \mathrm{mg} / \mathrm{kg}, p<0.05)$ and decreased $\mathrm{P}$ in males $(300$ $\mathrm{mg} / \mathrm{kg}, p<0.05)$. 
Table 5 Histopathology of rats on day 28 of subacute feeding test of Py-mulin

\begin{tabular}{|c|c|c|c|c|c|c|c|c|c|}
\hline \multirow[t]{3}{*}{ Organ } & \multirow[t]{3}{*}{ Histopathological characters } & \multicolumn{8}{|c|}{ 28-day $(n=10)$} \\
\hline & & \multicolumn{2}{|c|}{ Control } & \multicolumn{2}{|c|}{50 mg/kg b.w. } & \multicolumn{2}{|c|}{100 mg/kg b.w. } & \multicolumn{2}{|c|}{300 mg/kg b.w. } \\
\hline & & Female & Male & Female & Male & Female & Male & Female & Male \\
\hline \multirow[t]{3}{*}{ Liver } & Inflammatory cells & $1 / 5$ & $1 / 5$ & $2 / 5$ & $0 / 5$ & $2 / 5$ & $1 / 5$ & $1 / 5$ & $1 / 5$ \\
\hline & Congestion & $1 / 5$ & $0 / 5$ & $0 / 5$ & $0 / 5$ & $1 / 5$ & $1 / 5$ & $1 / 5$ & $2 / 5$ \\
\hline & Edema & $0 / 5$ & $0 / 5$ & $0 / 5$ & $1 / 5$ & $1 / 5$ & $0 / 5$ & $2 / 5$ & $1 / 5$ \\
\hline \multirow[t]{2}{*}{ Heart } & Erythrocytosis & $1 / 5$ & $0 / 5$ & $2 / 5$ & $0 / 5$ & $2 / 5$ & $1 / 5$ & $0 / 5$ & $1 / 5$ \\
\hline & Edema & $0 / 5$ & $0 / 5$ & $1 / 5$ & $0 / 5$ & $3 / 5$ & $0 / 5$ & $1 / 5$ & $0 / 5$ \\
\hline \multirow[t]{2}{*}{ Spleen } & Erythrocytosis & $0 / 5$ & $1 / 5$ & $0 / 5$ & $1 / 5$ & $1 / 5$ & $1 / 5$ & $1 / 5$ & $1 / 5$ \\
\hline & Congestion & $0 / 5$ & $0 / 5$ & $1 / 5$ & $0 / 5$ & $1 / 5$ & $1 / 5$ & $0 / 5$ & $1 / 5$ \\
\hline \multirow[t]{2}{*}{ Lungs } & Connective tissues proliferation & $1 / 5$ & $1 / 5$ & $1 / 5$ & $2 / 5$ & $1 / 5$ & $0 / 5$ & $2 / 5$ & $2 / 5$ \\
\hline & Congestion & $0 / 5$ & $1 / 5$ & $1 / 5$ & $0 / 5$ & $0 / 5$ & $0 / 5$ & $0 / 5$ & $2 / 5$ \\
\hline Ovaries & Congestion & $0 / 5$ & -- & $2 / 5$ & -- & $1 / 5$ & -- & $1 / 5$ & -- \\
\hline
\end{tabular}

\section{Macroscopic observation, absolute organ weight and relative organ weights}

There was no macroscopic pathological change in Pymulin treated groups on the 28th day. The organ weight and organ/body-weight ratios of female and male rats were summarized in Table 3 and Table 4. In female rats, there were significant increases $(p<0.05)$ in the absolute organ weight of the liver $(300 \mathrm{mg} / \mathrm{kg})$, and significantly increased $(p<0.05)$ in the relative weight of the liver $(300 \mathrm{mg} / \mathrm{kg})$ and the thymus $(100 \mathrm{mg} / \mathrm{kg})$ compared to that of the control group. In male rats, absolute thymus $(100 \mathrm{mg} / \mathrm{kg})$ weight was significantly decreased $(p<0.05)$ and the relative weight of testis $(100 \mathrm{mg} / \mathrm{kg})$ significantly increased $(p<0.05)$ compared to that of control group.

\section{Histopathological analysis}

Treatment-related changes in rat heart, liver, spleen, lungs, kidneys, thymus, small intestines, testes or ovaries were confirmed by H\&E histology analyses in the three dose groups of Py-mulin as compared to the control group. Evaluation of kidneys, thymus, testes and small intestines did not reveal any histopathological changes. Typically histopathological characters of liver, heart, spleen, lung and ovaries in control and the three treated groups were showed in Fig. 3 and Table 5. Various lesions, including mild congestion, inflammatory cells and edema in the liver (Fig. 3A), erythrocytosis and edema in heart (Fig. 3B), erythrocytosis and congestion in spleen (Fig. 3C), connective tissues proliferation and congestion in lungs (Fig. 3D) and congestion in ovaries (Fig. 3E) were observed in three treatment groups and control group. However, the severities of all of these lesions were minimal or slight.

\section{Ames test}

The results of the $S$. typhimurium reverse mutation assay for Py-mulin in the presence or absence of metabolic activation are shown in Table 6. Revertant colonies in all positive groups were much more than two-fold of colonies induced by five concentrations of Py-mulin and

Table 6 Ames test results of Py-mulin using S. typhimurium strains TA97, TA98, TA100, TA102 and TA1535

\begin{tabular}{|c|c|c|c|c|c|c|c|c|c|}
\hline \multirow[t]{2}{*}{ Substance } & \multirow{2}{*}{$\begin{array}{l}\text { Dose } \\
\text { ( } \mu \mathrm{g} / \\
\text { plate) }\end{array}$} & \multicolumn{2}{|l|}{ TA97 } & \multicolumn{2}{|l|}{ TA98 } & \multicolumn{2}{|l|}{ TA100 } & \multicolumn{2}{|l|}{ TA1535 } \\
\hline & & - S9 & $+S 9$ & - S9 & + S9 & - S9 & $+\$ 99$ & - S9 & + S9 \\
\hline \multirow[t]{5}{*}{ Py-mulin } & 1000 & $46.3 \pm 3.5^{* *}$ & $55.0 \pm 4.6^{* *}$ & $21.0 \pm 2.6$ & $19.7 \pm 3.5$ & $36.7 \pm 3.1^{* *}$ & $38.0 \pm 3.6^{* *}$ & $20.7 \pm 3.1$ & $27.3 \pm 2.5$ \\
\hline & 200 & $62.0 \pm 5.3$ & $62.7 \pm 4.2^{* *}$ & $22.7 \pm 3.1$ & $26.7 \pm 2.5$ & $83.7 \pm 4.5^{*}$ & $73.3 \pm 3.1^{* *}$ & $25.0 \pm 2.6$ & $38.7 \pm 3.5$ \\
\hline & 40 & $72.0 \pm 3.6$ & $77.7 \pm 3.2$ & $33.3 \pm 4.5$ & $28.0 \pm 4.9$ & $93.7 \pm 4.2$ & $89.0 \pm 8.5$ & $34.3 \pm 4.0$ & $41.7 \pm 4.7$ \\
\hline & 8 & $80.3 \pm 4.7$ & $79.3 \pm 5.1$ & $23.7 \pm 4.0$ & $24.7 \pm 5.5$ & $105.7 \pm 6.7$ & $101.3 \pm 3.5$ & $38.7 \pm 4.7$ & $36.7 \pm 5.0$ \\
\hline & 1.6 & $76.3 \pm 5.6$ & $94.3 \pm 4.0$ & $32.7 \pm 3.5$ & $31.7 \pm 3.1$ & $112.0 \pm 5.3$ & $115.0 \pm 5.0$ & $42.0 \pm 4.4$ & $44.3 \pm 5.5$ \\
\hline \multicolumn{2}{|c|}{ Vehicle control } & $84.0 \pm 5.0$ & $98.3 \pm 5.1$ & $24.7 \pm 3.5$ & $29.7 \pm 2.1$ & $111.3 \pm 4.2$ & $120.0 \pm 5.6$ & $34.7 \pm 4.2$ & $43.3 \pm 5.7$ \\
\hline \multicolumn{2}{|c|}{ Positive control } & $737.3 \pm 13.3^{* *}$ & $964.7 \pm 13.0^{* *}$ & $567.7 \pm 11.5^{* *}$ & $614.0 \pm 15.1^{* *}$ & $913.3 \pm 20.8^{* *}$ & $1212.3 \pm 12.9^{* *}$ & $583.0 \pm 13.7^{* *}$ & $746.3 \pm 12.6^{* *}$ \\
\hline
\end{tabular}

Note: The numbers indicate the means and standards deviation values of CFU in triplicate assay systems

+ S9: with metabolic activation; - S9: without metabolic activation

Vehicle contro: DMSO (100 $\mu \mathrm{L} /$ plate $)$

Positive control: 2-aminofluorene for all strains with S9; Fenaminosulf for all strains without S9

${ }^{*} p<0.05,{ }^{* *} p<0.01$ vs. vehicle control 
vehicle control $(100 \mu \mathrm{L} /$ plate $\mathrm{DMSO})$. Py-mulin at $1000 \mu \mathrm{g} /$ plate significantly decreased the number of revertant colonies of TA97 (-S9 and + S9) and TA100 (-S9 and + S9) due to its antibacterial property. At $200 \mu \mathrm{g} /$ plate, Py-mulin also significantly decreased the number of revertant colonies of TA97 (+S9) and TA100 (-S9 and + S9). However, no significantly different between the number of revertant colonies induced by the vehicle control and Py-mulin at the 40,8 or $1.6 \mu \mathrm{g} /$ plate was observed.

\section{Discussion}

Toxicity assessment is an essential process during the development and application of a new drug. This study evaluated the acute, subacute oral toxicity and genotoxicity of Py-mulin, a novel pleuromutilin derivative with a substituted pyrimidine moiety.

In the acute phase of the study, exposure of mice to a single dose of 55,175 and $550 \mathrm{mg} / \mathrm{kg}$ did not produce any mortality and alterations in adverse clinical signs. However, a single dose of 1750 and 5000 $\mathrm{mg} / \mathrm{kg}$ of Py-mulin showed clinical signs of acute toxicity and 20 and $70 \%$ mortality on the 3th day of post-dosing, respectively. The calculated $\mathrm{LD}_{50}$ values for Py-mulin were $2973 \mathrm{mg} / \mathrm{kg}$ (female mice) and $3891 \mathrm{mg} / \mathrm{kg}$ (male mice) which were all significant higher than that of tiamulin $(1580 \mathrm{mg} / \mathrm{kg}$ in mice), and valnemulin $(1710 \mathrm{mg} / \mathrm{kg}$ in mice), two pleuromutilin drugs used for veterinary $[28,29]$. This reflected the low acute toxicity of Py-mulin in comparison with the same class drugs.

The 28-day subacute oral toxicity study of Py-mulin in rats showed similar mean body weights among the four groups during the experiment. Furthermore, this study revealed no test substance-related effects on body weights, food consumption or clinical signs, in any rats in the treatment groups up to $300 \mathrm{mg} / \mathrm{kg} \mathrm{b}$. w.

Hematological levels which are measured in the animal studies can be used to assess the risk of toxicity for human $[24,30]$. All animals in the treated groups did not show any significant change when compared to that of the control. Only a few significant changes in hematological values (RBC, HCT and $\mathrm{MCV}$ ) were observed in both female and male animals, but they were fluctuated within the physiological norm. The increase levels of AST ALP and ALT in the blood are associated with damage of hepatic cells [31]. The administration of Py-mulin in this subacute study caused a significant increase in the levels of ALT in female rats at 100 and $300 \mathrm{mg} / \mathrm{kg}$ dose. The levels of ALP also increased significantly in the male rats but decreased slightly in the female rats. Furthermore, the elevated levels of triglycerides, bilirubin and cholesterol and reduction in albumin are other significant indicators of failure in hepatic function [32, 33]. But in our study, the repeated administration of Py-mulin did not show any significant change in the level of triglycerides, cholesterol and albumin. In general, the hematological and biochemical changes were not dose-dependent.

At necropsy, the increase of both absolute and relative weight in the female rate liver was dosedependent. Statistically significant differences were further observed in the $300 \mathrm{mg} / \mathrm{kg}$ female group. Furthermore, our further histopathological study showed the lesions in the liver, heart, spleen, lung and ovaries were sporadically detected in controls and the treated rats. But these observed histopathological changes were more in female than that in male rats in treatment groups. Combined with the result that Py-mulin with 100 and $300 \mathrm{mg} / \mathrm{kg}$ doses caused significant increase of ALT in female rats, it could be concluded that Py-mulin display slightly hepatotoxicity to female rats with 100 and $300 \mathrm{mg} / \mathrm{kg}$ doses.

For evaluating the genotoxic activity of a chemical agent, the Ames test is an initial in vitro screening method with rapid and effective properties [34, 35]. Four S. typhimurium strains TA97, TA98, TA100 and TA1535 with and without S9 metabolic activation were employed in the present study. The sensitivity of our Ames test was demonstrated by the facts that the chemicals in positive control group significantly increased the counts of corresponding mutant strain than that in vehicle control group. Due to its antibacterial property, the higher concentrations of Py-mulin decreased the number of revertant colonies, especially the TA97 and TA100 strains. In the presence and absence of S9, exposure to Py-mulin at 40, 8 and $1.6 \mu \mathrm{g} /$ plate, respectively, did not display any inhibitory effect on the growth of S. typhimurium, indicating that the four strains were tolerant to these concentrations. Moreover, Py-mulin with all tested concentrations did not increase the counts of revertant colonies significantly in four strains with or without $\mathrm{S} 9$ activation.

\section{Conclusions}

In summary, the acute toxicity study showed no acute toxicity for Kunming mice after the oral administration of Py-mulin up to $550 \mathrm{mg} / \mathrm{kg}$, but indicated the acute oral lethal dose was more than $1750 \mathrm{mg} / \mathrm{kg}$ with an approximate $\mathrm{LD}_{50}$ of $2973 \mathrm{mg} / \mathrm{kg}$ (female mice) and 3891 $\mathrm{mg} / \mathrm{kg}$ (male mice). The subacute oral toxicity study suggested that no biologically significant differences were observed in hematology, clinical chemistry, organ weights, or histopathology between $50 \mathrm{mg} / \mathrm{kg}$ treatment group and the control group. However, in female rats, hepatotoxicity was more likely to occur 
than the other examined organs following higher dose of Py-mulin (100 and $300 \mathrm{mg} / \mathrm{kg})$. Ames test revealed that Py-mulin at concentrations of $1.6-1000 \mu \mathrm{g} / \mathrm{plate}$ did not induce gene mutation in the four standard $S$. typhimurium strains.

\section{Abbreviations}

Alb: Albumin; ALP: Alkaline phosphatase; ALT: Alanine transaminase; ANOVA: One-way analysis of variance; APTM: 14-O-[(4-Amino-6-hydroxypyrimidine-2-yl) thioacetyl] mutilin; AST: Aspartate transaminase; $B$. subtilis: Bacillus subtilis; Ca: Calcium; Crea: Creatinine;

EDTA: Ethylenediaminetetraacetic acid; Glu: Glucose; GM: Glucose minimal; HCT: Hematocrit; HDL: High density lipoprotein; HGB: Hemoglobin; LDL: Low density lipoprotein; $\mathrm{MCH}$ : Mean corpuscular hemoglobin; MCHC: Mean corpuscular haemoglobin concentration; MCV: Mean corpuscular volume; MDR: Multidrug resistant; MRSA: Methicillin-resistant Staphylococcus aureus; OECD: Organization for economic cooperation and development; P: Phosphorous; PBS: Phosphate buffer saline; PLT: Platelets; RBC: Red blood cell; S. aureus: Staphylococcus aureus; SD: Sprague-Dawley; SPF: Specific pathogen free; TB: Total bilirubin; TC: Total cholesterol; TG: Triglycerides; TP: Total protein; UN: Urea nitrogen; WBC: White blood cell

\section{Acknowledgements}

We thank all those who provided excellent technical support and assistance during the study.

\section{Authors' contributions}

RFS and YF designed the study. RFS drafted the manuscript and draw the Figs. YL and $\mathrm{BCH}$ revised the manuscript for important intellectual content. RFS finished data statistics and analysis. YF, YXF and YHZ planned and finished the experiments. All the authors have read and approved the final version of the manuscript.

\section{Funding}

This work was supported by the National Natural Science Foundation of China (No. 31873027), "Quancheng Scholar" Construction Project of Jinan (No. 00252019025) and Agricultural Science and Technology Innovation Program (ASTIP, CAAS-LMY-03). The study funder had no further role in the study design, data collection, analyses, interpretation of results, writing of the article, or the decision to submit it for publication.

\section{Availability of data and materials}

The datasets supporting the conclusions of this article are included within the article. The raw data can be requested from the corresponding author.

\section{Declarations}

\section{Ethics approval and consent to participate}

Approval of the study protocol was obtained from the Committee for Ethics in the Laboratory Animal Center of Lanzhou University (number: SCXK20130002).

\section{Consent for publication}

Not applicable.

\section{Competing interests}

The authors declare that there are no conflicts of interest.

\section{Author details}

${ }^{1}$ Key Laboratory of New Animal Drug Project, Gansu Province/Key Laboratory of Veterinary Pharmaceutical Development, Ministry of Agriculture and Rural Affairs/Lanzhou Institute of Husbandry and Pharmaceutical Sciences of Chinese Academy of Agriculture Sciences, No. 335, Qilihe District, Lanzhou 730050, People's Republic of China. ${ }^{2}$ Zhengzhou Key Laboratory of Immunopharmacology of effective components of Chinese Veterinary Medicine, College of Veterinary Medicine, Henan University of Animal Husbandry and Economy, 450046 Zhengzhou, People's Republic of China.
Received: 2 July 2021 Accepted: 17 December 2021

Published online: 04 January 2022

\section{References}

1. Parmar A, Lakshminarayanan R, lyer A, Mayandi V, Goh ETL, Lloyd DG, et al. Design and syntheses of highly potent teixobactin analogues against Staphylococcus aureus, methicillin-resistant Staphylococcus aureus (MRSA), and vancomycin-resistant enterococci (VRE) in vitro and in vivo. J Med Chem. 2018;61(5):2009-17. https://doi.org/10.1021/acs.jmedchem.7b01634.

2. Chatzopoulou M, Reynolds L. Role of antimicrobial restrictions in bacterial resistance control: a systematic literature review. J Hosp Infect. 2020;104(2): 125-36. https://doi.org/10.1016/j.jhin.2019.09.011.

3. Ventola CL. The antibiotic resistance crisis: part 1: causes and threats. Pharm Ther. 2015;40:277

4. Astolfi A, Felicetti T, Iraci N, Manfroni G, Massari S, Pietrella D, et al. Pharmacophore-based repositioning of approved drugs as novel Staphylococcus aureus norA efflux pump inhibitors. J Med Chem. 2017;60(4): 1598-604. https://doi.org/10.1021/acs.jmedchem.6b01439.

5. Yarlagadda V, Samaddar S, Paramanandham K, Shome BR, Haldar J. Membrane disruption and enhanced inhibition of cell-wall biosynthesis: a synergistic approach to tackle vancomycin-resistant bacteria. Angew Chem Int Ed. 2015;54(46):13644-9. https://doi.org/10.1002/anie.201507567.

6. Kavanagh F, Hervey A, Robbins WJ. Antibiotic substances from Basidiomycetes: VIII. Pleurotus multilus (Fr.) Sacc. And Pleurotus passeckerianus Pilat. Proc Natl Acad Sci U S A. 1951;37(9):570-4. https://doi.org/10.1073/pna s.37.9.570.

7. Novak R, Shlaes DM. The pleuromutilin antibiotics: a new class for human use. Curr Opin Investig Drugs. 2010;11(2):182-91.

8. Shang RF, Wang JT, Guo WZ, Liang JP. Efficient antibacterial agents: a review of the synthesis, biological evaluation and mechanism of pleuromutilin derivatives. Curr Top Med Chem. 2013;13(24):3013-25. https:/ doi.org/10.2174/15680266113136660217.

9. Schlunzen F, Pyetan E, Fucini P, Yonath A, Harms JM. Inhibition of peptide bond formation by pleuromutilins: the structure of the 50 ribosomal subunit from Deinococcus radiodurans in complex with tiamulin. Mol Microbiol. 2004;54(5):1287-94. https://doi.org/10.1111/j.1365-2958.2004.0434 6.x.

10. Davidovich C, Bashan A, Auerbach-Nevo T, Yaggie RD, Gontarek RR, Yonath A. Induced-fit tightens pleuromutilins, binding to ribosomes and remote interactions enable their selectivity. Proc Natl Acad Sci U S A. 2007;104(11): 4291-6. https://doi.org/10.1073/pnas.0700041104.

11. Novak R. Are pleuromutilin antibiotics finally fit for human use? Ann N Y Acad Sci. 2011;1241(1):71-81. https://doi.org/10.1111/j.1749-6632.2011.06219. $x$.

12. Fazakerley NJ, Procter DJ. Synthesis and synthetic chemistry of pleuromutilin. Tetrahedron. 2014;70(39):6911-30. https://doi.org/10.1016/j. tet.2014.05.092.

13. Shang RF, Pu XY, Xu XM, Xin ZJ, Zhang C, Guo WZ, et al. Synthesis and biological activities of novel pleuromutilin derivatives with a substituted thiadiazole moiety as potent drug-resistant bacteria inhibitors. J Med Chem. 2014;57(13):5664-78. https://doi.org/10.1021/jm500374c.

14. Tang YZ, Liu YH, Chen JX. Pleuromutilin and its derivatives-the lead compounds for novel antibiotics. Mini-Rev Med Chem. 2012;12(1):53-61. https://doi.org/10.2174/138955712798868968.

15. Li YG, Wang JX, Zhang GN, Zhu M, You XF, Wang YC, et al. Design, synthesis, and biological activity evaluation of a series of pleuromutilin derivatives with novel C14 side chains. Bioorg Med Chem Lett. 2020;30(7): 126969. https://doi.org/10.1016/j.bmcl.2020.126969.

16. Burch DG. Tiamulin activity against Brachyspira hyodysenteriae. Vet Rec. 2008; 163(25):760.

17. Stipkovits L, Ripley PH, Tenk M, Glavits R, Molnar T, Fodor L. The efficacy of valnemulin (Econor) in the control of disease caused by experimental infection of calves with mycoplasma bovis. Res Vet Sci. 2005;78(3):207-15. https://doi.org/10.1016/j.rvsc.2004.09.005.

18. Scangarella-Oman NE, Shawar RM, Bouchillon S, Hoban D. Microbiological profile of a new topical antibacterial: retapamulin ointment 1\%. Expert Rev Anti-Infect Ther. 2009;7(3):269-79. https://doi.org/10.1586/eri.09.7.

19. FDA. FDA approves new antibiotic to treat community-acquired bacterial pneumonia. 2019. https://www.fda.gov/news-events/press-announcements/ fda-approves-new-antibiotic-treat-community-acquired-bacterial-pneumonia. 
20. Powell D, Donato A. In community-acquired bacterial pneumonia, lefamulin was noninferior to moxifloxacin at $96 \mathrm{~h}$ after the first dose. Ann Intern Med. 2020;4:JC22-Jc22.

21. Zhang YY, Chuan XL, Yang L, Shang F, Shao RS, Yu J, et al. Synthesis, biological activities and docking studies of pleuromutilin derivatives with piperazinyl urea linkage. J Enzym Inhib Med Ch. 2021;36(1):764-75. https:/ doi.org/10.1080/14756366.2021.1900163.

22. Yi YP, Yang GZ, Zhang C, Chen JR, Liang JP, Shang RF. Synthesis and evaluation of novel pleuromutilin derivatives with a substituted pyrimidine moiety. Eur J Med Chem. 2015;101:179-84. https://doi.org/10.1016/j. ejmech.2015.06.034.

23. OECD. Test No. 407: OECD Guidelines for the Testing of Chemicals. Repeated dose 28-day Oral Toxicity Study in rodents. Paris: OECD Publishing; 2008. Section 4

24. Christapher PV, Parasuraman S, Asmawi MZ, Murugaiyah V. Acute and subchronic toxicity studies of methanol extract of polygonum minus, leaves in Sprague Dawley rats. Regul Toxicol Pharmacol. 2017;86:33-41. https://doi. org/10.1016/j.yrtph.2017.02.005.

25. Wahab NFAC, Kannan TP, Mahmood Z, Rahman IA, Ismail H. Genotoxicity assessment of biphasic calcium phosphate of modified porosity on human dental pulp cells using Ames and comet assays. Toxicol in Vitro. 2018;47: 207-12. https://doi.org/10.1016/j.tiv.2017.12.002.

26. Nelma DMO, Marielly RR, Daniel AM, Gisela U, Marcelo FGB. In vitro mutagenicity assay (Ames test) and phytochemical characterization of seeds oil of helianthus annuus linné (sunflower). Toxicol Reports. 2016;3:733-9. https://doi.org/10.1016/j.toxrep.2016.09.006.

27. IBM Corp. Released 2016. IBM SPSS Statistics for Windows, Version 24.0. Armonk: IBM Corp.

28. Wang LP, Jiang SX, Shi XL, Wan RF, Guo YG, Feng XJ. Tamulin: the antimicrobial susceptibility in vitro and the common toxicity in viro. Anim Husbandry Vet Med. 2004;36:4-6.

29. EMEA. The European Agency for the evaluation of medicine products, Veterinary medicines evaluation unit: Valnemulin, Summary Report [EB/OL] 2002. http://www.emea.europa.eu/vetdocs/PDFs/EPAR/econor/003199en6. pdf.

30. Hor SY, Ahmad M, Farsi E, Yam MF, Hashim MA, Lim CP, et al. Safety assessment of methanol extract of red dragon fruit (hylocereus polyrhizus): acute and subchronic toxicity studies. Regul Toxicol Pharmacol. 2012;63(1): 106-14. https://doi.org/10.1016/.yrtph.2012.03.006.

31. Andreia RH, Reginato FZ, Guex CG, Kássia CF, Araldi ICDC, Freitas RBD. Acute and sub-chronic (28 days) oral toxicity evaluation of tincture baccharis trimera (less) backer in male and female rodent animals. Regul Toxicol Pharmacol. 2016;74:170-7. https://doi.org/10.1016/j.yrtph.2015.10.024.

32. Li YS, Kandhare AD, Mukherjee AA, Bodhankar SL. Acute and sub-chronic oral toxicity studies of hesperidin isolated from orange peel extract in Sprague Dawley rats. Regul Toxicol Pharmacol. 2019;105:77-85. https://doi. org/10.1016/.jyrtph.2019.04.001

33. Han ZZ, Koo KH, Kim KH, Bae JS, Shin SH, Kim HS, et al. Acute and 90-day subchronic toxicity studies of silk peptide e $5 \mathrm{k} 6$, in Sprague-Dawley rats. Food Chem Toxicol. 2011;49(9):2410-4. https://doi.org/10.1016/j.fct.2011.06. 058.

34. Pukalskienė M, Slapšytė G, Dedonytė J, Lazutka JR, Mierauskiené J, Venskutonis PR. Genotoxicity and antioxidant activity of five agrimonia and filipendula species plant extracts evaluated by comet and micronucleus assays in human lymphocytes and Ames salmonella/microsome test. Food Chem Toxicol. 2018;113:303-13. https://doi.org/10.1016/j.fct.2017.12.031.

35. Li JY, Kong XJ, Li XW, Yang YJ, Zhang JY. Genotoxic evaluation of aspirin eugenol ester using the Ames test and the mouse bone marrow micronucleus assay. Food Chem Toxicol. 2013;62:805-9. https://doi.org/10.1 016/j.fct.2013.10.010.

\section{Publisher's Note}

Springer Nature remains neutral with regard to jurisdictional claims in published maps and institutional affiliations.

Ready to submit your research? Choose BMC and benefit from:

- fast, convenient online submission

- thorough peer review by experienced researchers in your field

- rapid publication on acceptance

- support for research data, including large and complex data types

- gold Open Access which fosters wider collaboration and increased citations

- maximum visibility for your research: over $100 \mathrm{M}$ website views per year

At BMC, research is always in progress.

Learn more biomedcentral.com/submissions 